\title{
LA ASISTIBILIDAD IN PERPETUUM: LOS TRASTORNOS MENTALES SEVEROS
}

\author{
OsCAR LAMORA GIRAL \\ Máster en Antropología Médica y Salud Global \\ Universitat Rovira i Virgili \\ oscarlamora@gmail.com
}

Resumen: Para poder ser introducido en el particular circuito de cuidados y saberes terapéuticos propios de cada sistema médico el sujeto debe ser significado como asistible. El hecho de que alguien adquiera tal categoría estará íntimamente relacionado con las representaciones culturales que sobre los padecimientos humanos establece cada sociedad. Partiendo de esta hipótesis, consideramos que, del mismo modo que es necesario que la sociedad reconozca al enfermo como tal, dicha condición solo podrá ser retirada a partir de un pool de expectativas y representaciones elaboradas ad hoc. Aspectos que no tienen por qué corresponderse con el cese de una sintomatología, la desaparición de unas evidencias biológicas o la remisión del sufrimiento subjetivo del afectado. A este proceso de desmarque social lo denominaremos proceso desistencial. El presente trabajo etnográfico describe y analiza los pormenores de este proceso en relación con un grupo de patologías psiquiátricas clasificadas como Trastornos Mentales Severos (TMS).

PALABRAS ClAVE: trastornos mentales; proceso asistencial; estigma; cronicidad; etnografía 
ABSTRACT: To be included in the health care system of each society, the individual must be regarded as worthy of attention. The fact that someone is regarded as such is closely related to the cultural representations that each society stipulates about human afflictions. Under these circumstances, we consider that, in the same way society needs to recognise a patient as such, this condition will only be withdrawn according to a pool of expectations and representations on an ad hoc basis. These don't necessarily correspond with the cessation of symptomatology, disappearance of biological evidence or referral of the subjective suffering in the affected person. This process of social deselection can be described as a "desistencial" process. The current ethnographic investigation describes and analyses the details of this process in relation to a group of psychiatric pathology classified as Severe Mental Disorders (SMD).

KEYWORDS: mental disorders; sickness process; stigma; chronicity; ethnography 
I am but mad north-north-west.

When the wind is southerly,

I know a hawk from a handsaw.

Hamlet, William Shakespeare

Este artículo recoge parte de un proyecto etnográfico de investigación realizado durante la primera mitad de 2019. Partiendo de lo escrito por los teóricos de los procesos asistenciales (Comelles, 1985; Freidson, 1978 [1970]; Goffman, 2001 [1961]; Haro, 2000; Kleinman, 1980) y la forma en cómo la medicina clasifica e identifica sus objetos de estudio (Fleck, 1986 [1935]; Hacking, 1996 [1983]), hemos profundizado acerca de los condicionantes socioculturales que a la postre pueden dificultar el desmarque médico y social de aquellos pacientes diagnosticados con trastornos ${ }^{1}$ mentales severos (TMS). Para ello hemos entrevistado a personas afectadas de diversas patologías mentales, de entre 40 y 65 años, indistintamente hombres y mujeres, todas ellas dentro del grupo nosográfico mencionado. En menor medida, hemos conversado también con monitores de asociaciones y centros de día dedicados a dar apoyo a enfermos mentales. Igualmente, hemos hecho uso de un conjunto de entrevistas realizadas a varios psiquiatras madrileños en el curso de un proyecto anterior acerca del internamiento urgente involuntario desarrollado durante la primera mitad de 2017.

En total han sido un conjunto de 13 entrevistas semiestructuradas, obtenidas de un muestreo en cadena o bola de nieve, bajo los siguientes tópicos: $a$ ) itinerarios diagnósticos, $b$ ) aceptación de la enfermedad, c) tratamientos, $d$ ) cotidianeidad social del paciente, $e$ ) expectativas personales y comunitarias en relación con el pronóstico. Las entrevistas han durado en torno a hora y media, han sido registradas en audio y se han desarrollado en espacios tan dispares como centros de día, terrazas de bares o domicilios particulares; todos ellos en las comunidades autónomas de Madrid y Aragón. Los nombres de las personas participantes y de las localizaciones geográficas más específicas han sido sustituidos por otros ficticios con el fin de preservar la intimidad de los informantes.

1 Los términos trastorno y enfermedad serán aquí utilizados en el sentido en el que la medicina institucional categoriza determinados estados emocionales, afectivos o perceptuales. 
Además de estas producciones, con la finalidad de triangular la información obtenida en el campo, hemos acudido a diversos manuales de diagnóstico clínico, guías institucionales, revistas especializadas, documentación legal y noticias de prensa.

\section{Clasificar}

La etiqueta paciente mental crónico nos concentra en una determinada zona de experiencia, sin embargo, al ser capaz de significar un espectro de perfiles tan amplio, nos confunde hasta el punto de no saber exactamente hacia quién debemos dirigir nuestro interés. Tanto si lo miramos desde el punto de vista de las designaciones institucionales y los sistemas expertos como si nos quedamos en la comprensión popular o la percepción subjetiva de enfermedad, cualquier caracterización aplicada no logrará abarcar el fenómeno en toda su extensión, hasta el punto de poder llegar a hacernos dudar de su misma existencia. No obstante, los enfermos mentales crónicos están ahí, las personas y las instituciones los identifican, lo que nos lleva a pensar que deben poseer una serie de cualidades o afectaciones particulares, aunque empíricamente no resulte fácil demostrarlo. En realidad, nos ocurriría más o menos lo mismo si buscáramos diseñadores, amas de casa o trabajadores del Campo de Gibraltar. Las categorías utilizadas, las clases mediante las que pensamos las personas, son analíticamente tan evanescentes como definitorias en cuanto a su función social.

El canadiense Ian Hacking (1996) nos pone en alerta sobre esta cuestión: «pensar» tiene más que ver con «intervenir» que con «representar». El conocimiento depende más de cómo se espera que este intervenga en la vida práctica que del deseo de aprehender una realidad ontológica escurridiza. Es por ello que las condiciones y expectativas sociales, todas ellas temporales y perentorias, van a determinar el surgimiento y la aceptación de unas determinadas categorías en detrimento de otras. Algo a lo que Hacking (2001) va a referirse como estilos de pensamiento, apropiándose del concepto Denkstil acuñado por el biólogo Ludwik Fleck (1986). Para este autor, todo hallazgo en el campo de las ciencias es propio de una época y de un colectivo de pensamiento particular. Más que del supuesto 
progreso lineal de la ciencia o de los avances tecnológicos de la humanidad, la consolidación de los conocimientos científicos es subsidiario y deudor de contextos socioculturales específicos que aceptan o rechazan determinadas representaciones en función de su adecuación a las condiciones socioestructurales de cada momento (Fleck, 1986).

Ian Hacking propone para ilustrar esta suerte de comportamiento epistemológico un sencillo y revelador ejemplo, muy oportuno al tema del presente artículo; algo que él denomina enfermedades mentales transitorias (Hacking, 1985; 1995; 1998). Conviene aclarar que el autor no está refiriéndose aquí a los padecimientos pasajeros de un paciente cualquiera sino a entidades clínicas que en los anales de la psiquiatría aparecen y desaparecen de forma abrupta en periodos de tiempo perfectamente localizables. Uno de los casos que expone es el bautizado como automatismo ambulatorio o fuguismo por la psiquiatría de finales del s. XIx. Según su acepción médica haría referencia a episodios disociativos en los que el sujeto abandona su habitual lugar de residencia, su comunidad o su trabajo para, sin ningún propósito ni cometido razonable, reaparecer en ciudades o países más o menos distantes (algo muy similar a nuestro turismo masivo).

Los viajeros locos ocuparon durante décadas un lugar preferencial dentro de las tan en boga rarezas psicopatológicas de la vida cotidiana que paulatinamente fueron emergiendo en el contexto de la pujante sociedad urbana. Sin embargo, años más tarde, este pintoresco comportamiento vino a declinar súbitamente como si de una pasajera epidemia microbiana se tratara, y con ello su interés médico y mediático ${ }^{2}$. O quizás no fuera del todo así. Para Hacking las causas de su casi total extinción serían más bien otras, nada que ver con virus y bacterias.

Las categorías que utilizamos para pensar y definir a las personas alteran sustancialmente nuestro mundo social. Si lo que pretendemos es arrojar una caracterización acerca de una desconocida bacteria, la cosa resultará, a priori, sencilla. Bastará con localizar un organismo, definir sus características morfológicas, sus mecanismos internos, someterlo a

2 En la tercera y cuarta edición del DSM (APA, 1980; APA, 1995), tras casi un siglo de ausencia, reaparece como fuga psicogénica y fuga disociativa respectivamente, sin embargo, sus criterios diagnósticos, el interés médico que se le concede, su prevalencia y su repercusión social van a dejar de ser los mismos. 
situaciones ambientales diversas, determinar su comportamiento, hacer lo mismo con alguno de sus congéneres y, por último, ponerle nombre y ubicarlo en un determinado orden taxonómico. Lo «sencillo» del caso está en que el comportamiento de tal microorganismo se debe a una serie de mecanismos internos y factores ambientales cuantificables y accesibles directa o indirectamente para el investigador, sujetos a un conjunto de leyes naturales universales, y sobre todo a que su capacidad de respuesta ante la categoría asignada va a ser nula . Entre el investigador y la bacteria no habrá lugar a dobles sentidos, metáforas o malentendidos, ni a ningún otro artefacto del lenguaje que implique múltiples significados. Su pequeña «relación de amor» no atenderá a otra razón que al deseo de escrutinio por parte del estudioso y a la fiabilidad de sus herramientas de exploración. La bacteria, muda bajo la lente del microscopio, jamás podrá imaginar que está siendo observada ni arrogarse, modificar o rechazar su nueva nomenclatura.

Para nada será así en el caso las ciencias sociales, ya que el foco va a recaer sobre entidades que en ningún caso van a permanecer indiferentes ante el acto de ser estudiadas y clasificadas. Hacking (2001) introduce el concepto clase interactiva para referirse a aquellas categorizaciones que aplicamos a personas, grupos o fenómenos sociales.

\section{Gráfico 1: Clase interactiva (Elaboración propia)}

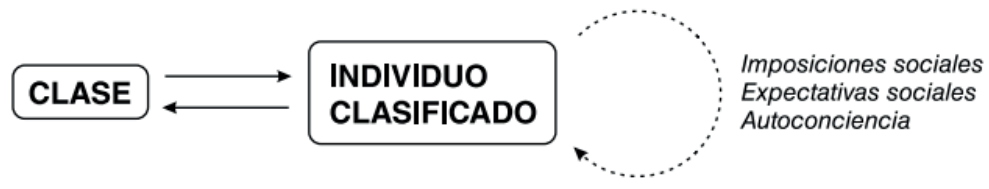

Al igual que los filósofos nominalistas o los teóricos del labeling (Becker, 2014; Lemert, 1967), Hacking defiende que las clasificaciones sociales imponen unos atributos y dinámicas que condicionan a los sujetos hasta el punto de convertirse en lo que dichas clasificaciones proponen ${ }^{4}$. Sin embargo, nuestro autor va a ir un poco más lejos al apuntar que los sujetos

3 A este tipo de categorías, características de las ciencias duras, Hacking (2001) las denomina clases indiferentes.

4 Algo a lo que Howard Becker (2014) llamó profecía autocumplida. 
clasificados, en su singularidad y praxis cotidiana, reformulan dichas categorías alterando su significado original y ajustándolo al conjunto de las exigencias sociales de cada momento. De este modo, la interacción se produce de forma bidireccional: de las categorías a las personas y de estas a las categorías, cerrando una suerte de bucle clasificatorio. Pero la cosa no quedaría ahí, ya que esta forma de asignar caracterizaciones posee también una vertiente retrospectiva. Es decir, los hechos del pasado, revisados a la luz de las nuevas categorías, van a incorporar nuevos sentidos no contemplados en el momento que acontecieron.

Lo que acaban haciendo este tipo de clases, según el autor canadiense, es inventar/construir gente (making up people) (Hacking, 1985). Se trataría de denominaciones que en sí mismas generan formas de ser/estar-en-el-mundo. Según esto, no habría sido posible ser esquizofrénico antes del siglo $\mathrm{xx}$, simplemente porque esa clase de personas no estaba todavía disponible; cosa que nada tiene que ver con la inexistencia de determinas experiencias subjetivas. $\mathrm{Ni}$ tampoco el tipo de persona que hoy designamos como esquizofrénico sería exactamente el que era en 1908. Ni sus criterios diagnósticos, ni los tratamientos, ni el pronóstico, ni la evolución, ni sus connotaciones sociales... todo ello aspectos en continua revisión derivada de los efectos de la interacción de las categorías con las personas y de las personas con las categorías.

A este respecto, es interesante recapitular la avalancha de divisiones y subdivisiones clasificatorias que, en todos los ámbitos, trajo consigo la modernidad y más concretamente la racionalidad administrativa del Estado. Censos de población, expedientes médicos, rangos militares, grados académicos, tipos de profesiones... (Hacking, 1985). Y es que para poder contar y ordenar gente, ejercicio paradigmático de la estadística ${ }^{5}$, resulta imprescindible tenerla identificada. Curiosamente, el campo del que surgieron mayor número de clasificaciones fue el ámbito de los malos comportamientos. El suicidio, el crimen, la indolencia, la prostitución, la locura, etc.; todo lo relativo a la moralidad será ordenado y cuantificado con una precisión y una minuciosidad en ocasiones obsesivas.

5 Tal y como indica su nombre, la estadística nace con el Estado. 
Esto nos traslada de nuevo a la racionalidad de la que, como entidad, hace uso la institución psiquiátrica y a sus tentativas taxonómicas. Las nosografías mentales han ido revisándose e incrementándose de forma excepcional a lo largo de estos dos siglos, con especial profusión en las últimas décadas. De tal modo que hemos pasado de unas cuantas entradas recogidas en el DSM-I (Manual Diagnóstico y Estadístico de los Trastornos Mentales) (APA, 1952) a una interminable plétora de trastornos, afecciones y problemas psicológicos. El DSM-I (APA, 1952) distinguía 106 entidades, el DSM-II 180 (1968), el DSM-III 265 (APA, 1980), el DSM-IV 297 (APA, 1995), el actual DSM-V (APA, 2014) recoge más de 400. Este delirio clasificatorio, más propio del inventario de una ferretería que de un programa médico, es capaz de tipificar cualquier clase de comportamiento humano. Lo cual actúa como un poderoso reglamento y una estereotipada guía de lo que oficialmente uno puede llegar a ser en términos psicopatológicos.

En su obra, Hacking extiende su hipótesis tan solo a determinadas clasificaciones, las ya mencionadas enfermedades mentales de época. A priori, a mi modo de ver, su postura supone una notable limitación analítica. Ya que si el fuguismo (ese comportamiento) puede ser considerado a partir de esta manera de inventar/construir gente, quizás puedan también serlo otras categorías sociales, incluyendo el rosario de caracterizaciones psicopatológicas que nos oferta la medicina psiquiátrica. De hecho, la historia de la psiquiatría estaría plagada de enfermedades mentales transitorias. Por citar algunos ejemplos, la histeria (Chauvelot, 2001), la neurastenia (Ehrenberg, 2000), la personalidad múltiple (Hacking, 1995) o la drapetomanía (Chorover, 1980). Todas ellas, desaparecidas o con ciertas vinculaciones, pero sin una correlación exacta con las nuevas nosografías, podrían perfectamente asimilarse como enfermedades mentales transitorias. Así pues, a falta de una mejor explicación, con la precaución que merece el tema, previniéndonos de no caer en ningún tipo de fetichismo metodológico, ¿quién es capaz de asegurar que el trastorno bipolar o la esquizofrenia no son una de ellas? Desde luego, tenemos la certeza de que determinados trastornos mentales existen, pero también de que antes no existían, de que en otras culturas no existen y de que no sabemos si dentro de unas pocas décadas existirán. 
Por el momento, tres van a ser nuestros puntos de partida: a) para que surja una determinada categoría nosográfica deben concurrir unas determinadas condiciones de posibilidad; $b$ ) al ser alguien clasificado, categorizado como una determinada cosa, le es asignada una nueva identidad social que va a condicionar sus hábitos y su comportamiento; c) el porvenir de dicha categoría va a estar sometido a la interacción con las personas así designadas y el resto de la sociedad.

\section{Padecer y parecer}

«No se vuelve loco el que quiere [sino el que puede]» (Lacan, 2005: 166). Curiosa afirmación que vamos a tomar al pie de la letra, puesto que si bien a lo que se refiere el psicoanalista francés es a la preexistencia de una estructura del lenguaje que posibilite la psicosis, de lo que aquí vamos a hablar es también de una estructura, una que reconozca la locura socialmente. Dos dimensiones aparentemente contrapuestas de un mismo fenómeno que pueden coincidir o no en relación con un conjunto de circunstancias culturales y expectativas sociales.

Tal y como señala Comelles (1999), para poder ser introducido en el particular circuito de cuidados y saberes propios de cada sistema médico es imprescindible que el sujeto pueda ser significado socialmente como asistible. El hecho de que alguien sea incluido en tal categoría estará intrínsecamente relacionado con las lógicas estructurales que sobre los padecimientos humanos establece cada sistema cultural, es decir, dependerá de cómo pueda llegar a ser representado colectivamente el sufrimiento, la enfermedad o la desviación. De ahí que podamos afirmar que para ser asistido no es suficiente con padecer o estar enfermo, sino que ante todo habrá que parecerlo a los ojos del resto.

Retomando la postura teórica de Ian Hacking, la condición asistible constituiría un tipo de clase interactiva surgida en el seno de una matriz patológica. Igualmente, el hecho de ser designado como asistible, especialista mediante o no, va a implicar una alteración en la percepción y el trato social hacia la persona afectada, de esta hacia sí misma y del influjo de sus prácticas y comportamientos hacia la categoría que le ha sido 
asignada. Una expresión realizativa (Austin, 1990) que va a consolidar un padecimiento legítimo y con ello una serie de cuidados y precauciones a nivel doméstico, comunitario e institucional.

\section{Un atributo profundamente desacreditante}

Tanto el trastorno bipolar como la esquizofrenia, y en menor medida algunos trastornos de la personalidad y disociativos, son afecciones calificadas por la medicina como trastornos mentales severos (TMS) (Gisbert et al, 2002). A diferencia de las aflicciones y los malestares, todos ellos sobresalen por sus elevadas tasas de cronicidad y el considerable grado de desadaptación social que provocan en el enfermo. Todos ellos, también, se caracterizan por su alto poder estigmatizador.

En el ámbito de la salud mental la palabra cronicidad tiene unas claras connotaciones negativas y estigmatizantes, razón por la que la literatura especializada viene utilizando más recientemente el término TRASTORNO MENTAL SEVERO (TMS) [en lugar de enfermedad mental crónica] para referirse a los trastornos mentales graves de duración prolongada y que conllevan un grado variable de discapacidad y disfunción social.»(Gisbert et alii, 2002: 5)

Llama la atención este estratégico cambio de denominación, ya que resulta bastante evidente que, aunque eliminemos el calificativo crónico de su denominación, el concepto trastorno mental severo conlleva unos requisitos diagnósticos y un tipo de tratamientos que siguen remitiéndonos a un grupo de patologías de carácter crónico. Es decir, más que de nombres, de lo que estamos hablando es de formas de clasificar a gente que a la postre va a acabar sufriendo las consecuencias de dichas clasificaciones.

La cronicidad sitúa el padecimiento en el orden del ser, una enfermedad de hoja perenne que no se tiene ni se está (enfermo), sino que, por el hecho de acompañarnos en todo tiempo y lugar sin que podamos deshacernos de ella, pasa a forma parte de nuestra mismidad social. Al igual que se es hombre, mujer, alto, negro, padre o huérfano, uno pasa a ser esquizofrénico o bipolar a través de un acto diagnóstico. A veces la 
enfermedad crónica no implica rechazo o lo hace muy sutilmente, sería el caso de afecciones como la diabetes o la celiaquía. Del mismo modo, no todas las enfermedades mentales provocan el mismo grado de aversión. Pero en otras ocasiones, cuando lo que se señala es la incorregibilidad de estados definidos por comportamientos reprobables o algún tipo de contaminación social (Douglas, 1973), la noción de cronicidad fija el atributo médico convirtiéndolo en estigma social; en palabras de Goffman (2006: 13), «un atributo profundamente desacreditante».

Todos nuestros informantes, explícita o implícitamente, refieren de forma recurrente situaciones de discriminación debida a su condición de enfermo mental. Con todo y con esto, gran parte de los psiquiatras entrevistados, obstinados en un planteamiento biomédico del problema, inciden en situar la dolencia en la dimensión del tener. Creen que al equiparar la locura con cualquier otra enfermedad desaparece el problema, como si lo que estuvieran diagnosticando fuera lo mismo que una amigdalitis o un cólico de riñón.

Cronicidad y psicosis no siempre ni en todo lugar han ido de la mano. De hecho, el término latino demencia hacía referencia a un estado de locura transitorio, para nada crónico ni irreversible; hasta bien entrado el s. XIX apenas se planteó la idea de cronicidad para la locura. Lanteri-Laura (1972) sitúa el origen de este binomio en el viraje degeneracionista del alienismo y en los grandes espacios manicomiales de finales de siglo. Según él, el giro hacia el degeneracionismo auspiciado por célebres psiquiatras de la época como Morel y Magnan, firmes defensores del origen anatomopatológico de la locura y de su transmisión hereditaria, suplantó la visión curativa que había profesado el inicial alienismo decimonónico por otra netamente asilar (Huertas, 2012; Peset, 1983). Al mismo tiempo, los espacios asilares, diseñados en base a su autosuficiencia económico-productiva, precisaron de una fuerza de trabajo constante para hacer frente al mercado que iba a ser encontrada en sus propios internos, lo cual coadyuvó en el establecimiento del binomio locura-cronicidad.

En otro orden de cosas, en relación con los diferentes marcos socioculturales, disponemos de estudios cuantitativos que muestran diferencias sustanciales en cuanto a la incidencia de la cronicidad en la salud 
mental. Los datos disponibles señalan que en 2017 había en el mundo 60 millones de afectados por trastorno bipolar y 21 por esquizofrenia (OMS, 2018). De ellos, los diversos estudios sobre la esquizofrenia, desarrollados por la OMS, muestran cómo las remisiones completas a largo plazo son significativamente mayores en países periféricos como India, Nigeria o Colombia, con un 37 \% de los casos, frente a tasas del 15 \% en Europa y Estados Unidos (Hopper et alii, 2007); lo que equivale a más del doble de los diagnosticados. Igualmente, los pacientes de países menos desarrollados disfrutan de una mejor integración comunitaria incluso estando mucho menos medicados, en una relación de consumo de antipsicóticos del $16 \%$ frente al 61 \% (Hopper et alii, 2007). En cuanto a la percepción que los diferentes grupos culturales tienen de la curabilidad también hallamos datos discordantes. Tal y como recoge Martínez-Hernáez (2006), los resultados son reveladores, ya que mientras el 81 \% de los euroamericanos afirman que los TMS no tienen curación, solamente el $31 \%$ de los hispanos afincados en Estados Unidos comparten tal pronóstico.

Dos conclusiones extraemos de todos estos datos. Por un lado, los síntomas de los TMS, aun despreciando que estas estadísticas solamente tienen en cuenta la población diagnosticada, no son algo inhabitual en la especie humana, por lo que este tipo de desviación no se establece en base a parámetros estadísticos; tal es así que, asumiendo sus caracterizaciones clínicas, probablemente haya más psicóticos que personas pelirrojas en el mundo. Por otro lado, la cronicidad aparece fuertemente asociada a las diferentes sensibilidades culturales en cuanto a la percepción social de la enfermedad. No sabemos si debido a las políticas públicas de salud, al tipo de soporte comunitario que reciben estos enfermos o simplemente a la forma de categorizar socialmente la enfermedad, la esquizofrenia y el trastorno bipolar no son exactamente lo mismo en unas que en otras latitudes culturales.

Por otro lado, sería interesante reflexionar acerca de a qué se refiere la medicina cuando afirma que una persona está curada o restablecida de su dolencia. Muchas veces, la idea de cronicidad aparece cuando la respuesta del paciente no se aproxima al ideal de curación esperado, que no 
tiene por qué ser necesariamente el retorno a la normalidad del paciente (ej. traumatismos, problemas odontológicos, quemados...).

En el mismo sentido, algunos trabajos (Vispe et alii, 2015) han denunciado las consecuencias que a la larga puede acarrear un diagnóstico tendencioso y determinista en el debut hospitalario de estos pacientes. Es el caso de la tradicional psicosis aguda o psicogénica, que en la terminología médica actual ha pasado a denominarse primer episodio psicótico, quedando fijada de este modo la idea de cronicidad.

Todos los pacientes de este estudio refieren siempre una primera experiencia o primer conflicto social que desemboca en un primer internamiento hospitalario, habitualmente involuntario, y que pasa a alterar irrevocablemente su realidad social por primera y definitoria vez.

Yo en mi caso entré por urgencias, en un episodio de manía, y la psiquiatra que había en urgencias ese día en 20 minutos consideró que yo tenía un trastorno bipolar, y de hecho me ingreso directamente. Con solo una entrevista. Entiendo que influyó también el hablar con la familia. Es una cosa un poco compleja, para nada científica, desde luego. [Lucas, paciente]

Según algunos autores, tras el internamiento estaríamos ante un sujeto ambiguo sin radicación social caracterizado por su ambigüedad (Alegre, 2016). Aspecto que es leído en clave de una suerte de perpetuación del estado liminal, una no-del-todo agregación social, un estado intersticial. A mi modo de ver, tras el acto de investidura médica, el sujeto quedaría perfectamente definido socialmente: un enfermo mental ${ }^{6}$. Y aunque desde la institución se insista en el mantra de la rehabilitación psicosocial, las acciones sociales que se le ofertan o directamente se le imponen, refuerzan su nueva condición social. Sometido a unas precauciones, unos cuidados, un trato social y unos espacios exclusivos de su nueva condición médica. Y si por algún casual se le olvida, la unidad de agudos siempre estará a la vuelta de la esquina para recordarle su nuevo papel en la sociedad. De ahí la alta tasa de reingresos, algo de lo que numerosos estudios

6 La ambigüedad de la locura da paso a la certeza de la enfermedad. 
han dejado constancia y que en el argot ha pasado a denominarse «síndrome de la puerta giratoria» (Prieto Oreja, 2016).

Así pues, entendemos que este proceso de resignificación social, de marcaje institucional, va a ser definitorio para el posterior desarrollo de la enfermedad. Sus aspectos centrales ya fueron abordados en mi anterior trabajo acerca del internamiento urgente involuntario ${ }^{7}$, por lo tanto, no nos detendremos más en ello. En esta ocasión queremos poner el foco sobre cuestiones determinantes para el mantenimiento de la etiqueta que acaba de ser adjudicada.

\section{Aceptación y resistencia}

Hemos visto como la asignación del criterio de cronicidad en salud mental juega un papel determinante en la consolidación del estigma médico. Del mismo modo, esta condición estigmatizada va a abocar a una serie de prácticas y posiciones sociales que finalmente van a cimentar $\mathrm{y}$ «perfeccionar» la categoría trastorno mental crónico, contribuyendo a crear aquello que Hacking (2001) refería como el efecto bucle de las clases humanas, para nuestro caso un genuino bucle psiquiátrico. Por ello, aparte de las propuestas clasificatorias que formula y reformula la institución, va a ser determinante la forma en la que el candidato incorpora estas caracterizaciones.

No todos los pacientes (ni su entorno), aceptan su nuevo rol de la misma manera. Los hay que se ciñen al guion establecido a las primeras de cambio, los hay que van asumiéndolo poco a poco, los hay que buscan intersticios en los que proseguir con una vida más o menos «normal», los hay que no entran nunca en el juego, y también están aquellos que, contra todo pronóstico, logran desmarcarse. Juanma, artista, con 20 años de carrera moral, a raíz de haber tenido un intento de suicidio, ha sido diagnosticado sucesivamente de trastorno límite de la personalidad, trastorno esquizoafectivo, trastorno narcisista,

7 Trabajo galardonado con el II Premio Antropológico Carmelo Lisón. Disponible en el website de la Fundación Lisón-Donald: <http://www.fundacionlison-donald.es/imagenes/autor_1/galeria_1/la_practica_social_del_iui.pdf>. 
y luego depresivo. Pero ya no hago ni caso porque si no acabaría encerrao. Si te lo crees ya la has cagao, lo conviertes en una forma de vida, además lo acentúas, porque he conocido gente que ha partido desde el mismo punto que yo, se han dejao llevar, no han luchao contra eso y se han convertido en perricos de la psiquiatría. [Juanma, paciente]

A diferencia de Juanma, la postura de Andrés, diagnosticado de trastorno bipolar y actualmente con una incapacidad asignada que lo inhabilita para cualquier ocupación laboral, es totalmente otra. Para él supone un alivio que «le hayan encontrao lo que le pasaba», puesto que le permite entender muchas cosas de su vida anterior. Tras varios ingresos en unidades de corta y media estancia, participa activamente en las actividades que organizan en la asociación para pacientes con trastorno mental, hacia la que se muestra profundamente agradecido. «Cuando te lo diagnostican te tienes que hacer a la idea que lo tienes y poner tus medios para no caer como hice yo este verano; llevar una vida tranquila y sosegada» [Andrés, paciente]. También está Lucas, que con el mismo diagnóstico que Andrés, pasa del tema e intenta llevar la misma vida que antes del brote, aunque su diagnóstico le permita estar en el centro especial de empleo donde trabaja. «Al principio me rayaba. Pero ahora yo estoy bien donde estoy, quiero decir, la etiqueta me permite tener este curro, y me mola el curro que hago y la relación con los compañeros [Lucas, paciente].

O Alicia, que no acaba de saber si lo suyo es esquizofrenia o trastorno bipolar, «no le importa lo que diga la gente» y está a la espera de una operación de riñón, probablemente asociada a los antipsicóticos que lleva tomando desde hace más de 30 años. O Lorenzo, que vive en una residencia de los servicios sociales, se pasa pintando todo el día en un centro de día y considera que las pastillas son sagradas y lo suyo es imposible de curar. O Mateo, un caso anómalo que, tras un brote psicótico con su respectivo mes de internamiento y varios años de psiquiatras y tratamientos, le fue diagnosticado Parkinson, lo cual lo desmarcó definitivamente de la etiqueta «enfermo mental».

Vemos cómo la manera de abrazar o impugnar el diagnóstico es de lo más diverso. Las entidades clasificadas son personas que reaccionan e interaccionan con la clasificación asignada. En ello influyen una serie de 
circunstancias personales tan diversas como pueden ser el tipo de apoyo familiar, la clase social, el género, el capital cultural, los signos de representación personal...; un conjunto de contingencias de carrera (Goffman, 2001) determinantes para el devenir vital de la persona afectada. Todos esos factores, relativos a la posición social del candidato, determinarán la forma como este y su entorno afronten una serie de actos médicos de investidura y dinámicas sociales que van a confirmar en mayor o menor medida la imagen estereotipada del enfermo mental.

Es indudable que los dispositivos de salud mental persiguen el beneficio del paciente, sería algo atroz pensar lo contrario. Sin embargo, los diseños y las inercias institucionales terminan, en muchas ocasiones, por aplicar unas medidas y el establecimiento de unas pautas acerca de las que, por el hecho de presentarse como incuestionables, rara vez se reflexiona dentro del ámbito médico. No solo el pronóstico desfavorable consolida la cronicidad y el estigma, determinadas intervenciones institucionales, aunque en teoría no lo pretendan, pueden llegar a hacerlo también. Por ejemplo, las medidas de contención, las incapacidades, las tutelas, los espacios de aislamiento o los eximentes legales. Todas ellas, asociadas a actuaciones que dan pie a la construcción social de un sujeto peligroso, indolente, insensato e imprevisible, además de incorregible. En aras de una prevención incondicional se tiende a reproducir un modelo de taxidermia psiquiátrica. De ahí que, más allá de la sacrosanta Reforma Psiquiátrica ${ }^{8}$ (Comelles, 1988; Huertas, 2017) y de las continuas campañas de desestigmatización que promueven las instituciones, a nadie debería extrañar que la sociedad en general piense lo que piensa de los enfermos mentales.

Muchas de estas medidas promocionan cierto grado de acomodo, acomodo que en muchos estudios cuantitativos se refleja en términos de cronicidad, puesto que los usuarios siguen computando como beneficiarios de unas ayudas y servicios sociales, aunque se sientan plenamente restablecidos. En el desarrollo de este trabajo he tenido la oportunidad de dialogar con personas que tenían una vida completamente «normal», libres de toda sintomatología desde hacía muchos años, con y sin medica-

8 Véase Ley General de Sanidad 14/1986, de 25 de Abril, BOE núm. 102, de 29/04/1986. 
ción, a los que su condición diagnóstica les repercutía económicamente una pensión que, a su vez, les impedía reincorporarse al mundo laboral.

En ocasiones, el acomodo puede venir dado por el mero hecho de ser asignada la clasificación, ya que posibilita una lectura retrospectiva de determinados comportamientos y conflictos sociales vividos en el pasado a la luz de la psicopatología. Es decir, el sujeto, guiado por el facultativo, encuentra en el diagnóstico biomédico la explicación a muchos de sus fracasos autobiográficos, lo cual puede proporcionarle cierto grado de despreocupación respecto a la dimensión social de su ser, a la par que otorga verosimilitud a la categoría asignada.

También en el plano familiar o comunitario se dan con frecuencia reacciones de acomodo. Cuando por ejemplo el sujeto se ve reiteradamente omitido, no se cuenta con él o todo lo que dice pasa a ser fruto de su enfermedad. O cuando es liberado de todo tipo de responsabilidades o se dan ciertas reacciones de miedo u hostilidad. Al final uno encuentra su lugar, el único lugar que el entorno le permite ocupar, haciendo de la locura un estilo de vida. «A nivel familiar, de alguna manera, se me trata como que no me cuentan nada, ni me hablan de ningún problema, como que tienen cuidado conmigo.» [Mateo, paciente]

Este aislamiento tiene su correlato en el tipo de relaciones sociales que el enfermo establece, muy habitualmente dentro de grupos de usuarios con los mismos problemas y vicisitudes sociales. Una communitas de estigmatizados en la que poder compartir sus experiencias con otros, sabedor de que no va a sentirse censurado. Gracias a pertenecer a esta, va a alejarse más y más de los «normales», reforzando su identidad desviada y dando un nuevo impulso a su carrera moral (Becker, 2014; Goffman, 2006). «Alguna vez he dicho como que no me fio de alguien que no ha tenido algún episodio psiquiátrico. Igual también porque me relacionaba con gente que lo había tenido» [Mateo, paciente].

Al igual que sucede con el entorno social, los lugares que estas personas pasan a frecuentar tras su etiquetado giran mayoritariamente alrededor de la enfermedad mental. Asociaciones, centros de día, ambulatorios, centros especiales de empleo...; espacios definidos por su función asisten- 
cial o terapéutica. Todo ello aglutina en torno a la institución a un ingente número de ciudadanos que en la práctica pasan a ser usuarios, acentuando aún más su dependencia y con ello su condición estigmatizada.

Y es que pocas cosas hay socialmente más contagiosas que el estigma, tanto por el riesgo para los que se relacionan con su portador (dime con quién vas y te diré quién eres), como por la facilidad que tiene para invadir el resto de parcelas de la vida del estigmatizado. Algo que da lugar a una enfermedad absoluta (Correa Urquiza, 2010) que mancha y contamina. Tal y como decía Howard Becker, «la posesión de un rasgo desviado pasa a tener un valor simbólico generalizado, de tal forma que la gente presupone automáticamente que su poseedor también tiene otros rasgos indeseables asociados» (Becker, 2014; 52).

En otro orden de cosas, es necesario señalar el poder iatrogénico y estigmatizante de los tratamientos antipsicóticos. La imagen de la locura ha variado a lo largo del último medio siglo en parte debido al uso masivo de estos medicamentos (Moncrieff, 2013; Pérez Álvarez, 2014). Más que tratamientos encaminados a restablecer algún tipo de función mental en el paciente, estamos ante camisas de fuerza químicas, con un alto grado de toxicidad, destinadas nada más que a contener comportamientos desordenados (Moncrieff, 2013; Hall, 2007; Pérez Álvarez, 2014). Podemos aceptar las virtudes de este tipo de fármacos en situaciones puntuales de crisis, como último recurso para contener determinados estados. Pero en realidad, los enfoques preventivos y los intereses de la industria farmacéutica ${ }^{9}$ los han convertido en tratamientos crónicos de primera elección. Alguna de las personas a las que he entrevistado para este trabajo apenas podían articular palabra. Tenían la boca seca, la cara aplanada, la mirada perdida. Esta imagen estereotipada del loco, tan presente en el imaginario colectivo, es una imagen moderna producto de un tratamiento terapéutico, para nada de una enfermedad. No es inocua ni accesoria. Ya que en la interacción social actúa como el inconfundible indicador de que estamos ante un enfermo mental.

9 Disease mongering: promoción o tráfico de enfermedades. Para más información véase Payer, 1992 
Yo les veo que no están con sus capacidades al cien por cien. La creatividad bastante coartada, no sé. Cuando les aciertan pues aún, pero es que hasta que les aciertan les meten de todo, entonces los puedes llegar a ver como super zombies. [Leonora, monitora]

Aparte de configurar «una imagen del loco» y producir unos efectos «no deseados», la droga ayuda a dar cuerpo a la noción de enfermedad. De algún modo, a falta de evidencias científicas, el fármaco viene a dar carta de naturaleza a la categoría, puesto que de todos es sabido que los medicamentos tratan enfermedades. En la actualidad, la mayor parte de los médicos consideran el uso de psicofármacos, ya no como un tratamiento de primera elección, sino como el único tratamiento posible. A partir de aquí, el papel al que acaba siendo relegado el psiquiatra es el de un profesional dedicado a retocar dosis, añadir o suprimir fármacos y persuadir a sus pacientes para que tomen su medicación. La relación médico-paciente y del paciente con su problema queda articulada casi exclusivamente en torno a la droga; obviando cualquier otro tipo de intercambio o intervención en su biografía o su condición como agente social. (Moncrieff, 2013; Martínez-Hernáez, 1998).

Una última observación en relación con lo que Lanteri-Laura (1972) comentaba acerca de los grandes espacios asilares decimonónicos: alrededor de la salud mental se ha generado una industria que moviliza una ingente cantidad de recursos y que precisa de médicos, fundaciones, gerentes, centros de día, auxiliares, monitores, farmacéuticas, investigadores... y sobre todo enfermos. Con ello no queremos decir que esta sea su razón de ser, pero sería ingenuo no tener en cuenta que la constitución de unas demandas materiales y profesionales implica la emergencia y consolidación de una estructura económica que va a imponer sus condiciones en cuanto a la perpetuación de una serie de problemas y demandas sociales. 


\section{Des-clasificar: un proceso desistencial ${ }^{\circ}$}

La locura no se cura y si se cura poco dura.

(Dicho popular)

Hemos hablado de cómo se llega a designar a alguien como «asistible» en salud mental, también del tipo de asistencia que a menudo recibe, igualmente hemos visto cómo ambos aspectos pueden favorecer la aparición del estigma y la consolidación de la cronicidad. Para concluir, me gustaría abordar las problemáticas y las dificultades que entraña dejar de ser un enfermo mental desde un punto de vista antropológico.

La reforma psiquiátrica española, gestada durante los años setenta e implementada en los ochenta (Comelles, 1988; Novella, 2017; Huertas, 2017; Alegre et al, 2018), tuvo como objeto desinstitucionalizar el tratamiento social de la enfermedad mental, hasta entonces fundamentalmente centrado en un modelo custodialista y forense. Al igual que otros países de Europa, fueron muchos los psiquiatras y autores nacionales que clamaron contra los perjuicios sociales, las reclusiones arbitrarias, la crueldad de los tratamientos o la cronificación de los pacientes; todas ellas problemáticas atribuidas a un modelo custodialista (Comelles, 1988; Huertas, 2017). Transcurridas más de tres décadas podemos observar cómo los manicomios han sido en gran medida borrados del mapa, sin embargo, afirmar que el modelo se ha desinstitucionalizado puede sonarnos a un brindis al sol. De hecho, la presencia de la institución se ha atomizado, volviéndose más ubicua e intervencionista ${ }^{11}$; la institución total (Goffman, 2001) ha derivado en institución total totalizante. Por lo que podemos llegar a la conclusión de que la reforma se quedó en un trastabillado proceso de «deshospitalización».

Tras ella han surgido nuevos problemas, nuevas demandas y un nuevo perfil de paciente, algo que en los ochenta se vino a llamar «nuevos crónicos» (Aparicio y Sánchez, 1990) y que posiblemente ya no se ajuste

10 Desistencia: desistimiento, del latín desistere, 'dejar de estar', derivado de sistere 'colocar', 'estar'. En contraposición a asistencia: del latín assistere, 'pararse junto a (un lugar)'

11 Tal y como anticipaba Michel Foucault en 1971, el desmantelamiento del manicomio «puede conducir a exportar la psiquiatría al exterior multiplicando sus intervenciones en la vida cotidiana» (Foucault, 1980: 41) 
al fenómeno actual. Un grupo heterogéneo de personas diagnosticadas con TMS que, sin haber pisado los antiguos psiquiátricos, muestran una gran dependencia hacia los múltiples servicios y prestaciones que oferta el dispositivo psiquiátrico y una tendencia a la cronicidad. En estos casos la cronicidad ya no se plantea estrictamente como sinónimo de «incurabilidad», sino «como una relación entre pacientes y terapeuta [dispositivo] ritualizada y estereotipada que no permite cambios, ni superar los conflictos internos de los sujetos, creando una relación de dependencia con el servicio asistencial durante largo tiempo» (Aparicio y Sánchez, 1990: 364).

Los «pacientes» con los que he podido charlar en este estudio conforman un grupo de personas que muestran una dependencia dispar hacia el dispositivo institucional. Hay desde los que únicamente cobran una pensión o acuden a algunas consultas hasta los que llegan a hacer del conjunto asistencial el centro de gravedad de sus vidas. Sin embargo, aun con sus diferencias, todos figurarían institucionalmente bajo el calificativo «enfermo mental crónico». Así pues, ¿hasta qué punto estamos ante una elección personal?, ¿en qué grado depende de la severidad de un cuadro clínico? ¿qué papel juegan las expectativas sociales y las inercias institucionales?

Mi conclusión al respecto es que una vez que el sujeto ha sido diagnosticado con un trastorno mental grave y ha entrado en el circuito asistencial, difícilmente va a poder desmarcarse. La marca de la imprevisibilidad, la discapacidad y el descrédito se torna prácticamente indeleble. No serían solamente los «síntomas» sino las expectativas y el tratamiento social los que van a abocar a la persona al ejercicio de un determinado tipo de vida, configurando de este modo una convincente imagen social del enfermo mental; compartida no solo por la población en general sino por las mismas instituciones que diseñan y aplican las clasificaciones. De este modo, para estas personas no hay dispositivo institucional o resorte cultural capaz de retirar su condición de «asistible», de ahí que el restablecimiento suela presentarse como algo formidablemente improbable.

Los comportamientos desviados existen y han existido en todas las sociedades, en cada una de ellas en relación con un marco normativo particular, que hace que una determinada conducta o ideación sea contem- 
plada como «anormal» y precise ser asumida en términos patológicos, sagrados, delictivos, etc. (Freidson, 1978). A su vez, cada uno de estos ejes contempla una serie limitada y estereotipada de formas de contravenir la norma. Tal y como defendieron Georges Devereux (1971) o François Laplantine (1979) en relación con los desórdenes étnicos, la sociedad estaría diciendo «no lo hagas, pero si lo haces, es preciso que lo hagas como te indico» (Devereux, 1971: 5). Es decir, la cultura, cualquiera, no solamente estructura el comportamiento correcto sino también el incorrecto.

Desde este punto de vista, la medicina psiquiátrica, que recordemos hunde sus raíces en la cultura europea de hace tan solo dos siglos, sería una etnocategoría productora de clases nativas. La particularidad que presentan a nivel social muchas de estas clases es que, a diferencia de los llamados desórdenes étnicos, de ellas uno difícilmente puede ser desmarcado. Algo que en gran medida delata que ya no hay lugar para determinadas formas de ser/estar en nuestro mundo preventivo, utilitarista e hipernormativizado. ${ }^{12}$ Con ello no estamos defendiendo que sea exclusivamente el diagnóstico el precursor de la enfermedad, al igual que tampoco aceptamos la idea opuesta, sino que ambas «se refuerzan mutuamente a modo de retroalimentación positiva». (Hacking, 2004: 279)

De este modo, observamos cómo el dispositivo asistencial no favorece el desmarque social del enfermo, al contrario, pudiera dar la sensación de que el influjo de la categoría diagnóstica aplicada altera de tal forma la percepción social del afectado que lo condena a unos cuidados y una vigilancia in perpetuum. Por ello, este trabajo defiende que, si lo que realmente se desea es desinstitucionalizar la enfermedad mental, el primer paso será desclasificarla, o al menos resignificar a conciencia las categorías con las que la institución nos provee. 


\section{Bibliografía}

Alegre, E. (2016). «Ethnoscapes domésticos y rite de passage: significación y cronicidad del diagnóstico en esquizofrenia». Revista de Antropología Social, 25(1), 195-217.

Alegre, E.; Barceló, J. y Comelles, J. M. (2018). «La confusión de los psiquiatras. Las narrativas en torno a la crisis del custodialismo durante el tardofranquismo». Revista de Historia de la Psicología, Vol. 39(1), 31-39 Aparicio, V. y SÁNCHEZ, A. E. (1990). «Desinstitucionalización y cronicidad: Un futuro incierto.» Revista Asociación Española Neuropsiquiatría, Vol. X. N. 034.

Asociación Americana De Psiquiatría, (APA), (1952). DSM-I. Diagnostic and Statistical Manual of Mental Disorders. American Psychiatric Association, Washington.

-(1968). DSM-II. Diagnostic and Statistical Manual of Mental Disorders. American Psychiatric Association, Washington.

-(1980). DSM-III. Diagnostic and Statistical Manual of Mental Disorders, American Psychiatric Association, Washington.

-(1995). DSM-IV. Manual diagnóstico y estadístico de los trastornos mentales. Masson, Barcelona.

-(2014). DSM-V. Manual diagnóstico y estadístico de los trastornos mentales. Editorial Médica Panamericana, Madrid.

Austin, J. (1990). Cómo hacer cosas con palabras. Paidós, Barcelona.

Becker, H. (2014). Outsiders. Hacia una sociología de la desviación. Siglo XXI, Buenos Aires.

Chauvelot, D. (2001). Historia de la histeria. Alianza Editorial, Madrid.

Chorover, s. (1980). «Mental health as a social weapon». En Richardson, H., New Religions and Mental Health: Understanding the Issues (pp. 14-19). Edwin Mellen Press, Nueva York.

Comelles, J. M. (1985). «Sociedad, salud y enfermedad: Los procesos asistenciales». Jano, 6-17 junio, n. ${ }^{\circ} 655-\mathrm{H}, 71-86$.

-(1988). La razón y la sinrazón. Asistencia psiquiátrica y desarrollo del Estado en la España Contemporánea. PPU, Barcelona. 
-(1999). «De la ayuda mutua y de la asistencia como categorías antropológicas. Una revisión conceptual». Actas III Jornadas Aragonesas de Educación para la Salud, 49-64.

-(2003). «Cultura y salud. De la negación al regreso de la cultura en medicina.» Quaderns de l'Institut Català d'Antropologia, Núm. 19, 111-131.

Correa URQuiza, M. (2010). Radio Nikosia: La rebelión de los saberes profanos (otras prácticas, otros territorios para la locura). Publicacions URV, Tarragona.

Devereux, G. (1971). Ensayos de etnopsiquiatría general. Barral Ediciones, Barcelona.

Douglas, M. (1973). Pureza y peligro. Siglo XXI, Madrid.

Ehrenberg, A. (2000). La fatiga de ser uno mismo. Depresión y sociedad. Nueva Visión, Buenos Aires.

FLECK, L. (1986). La génesis y el desarrollo de un hecho científico (ed. original 1935). Alianza Editorial, Madrid.

Foucault, M. (1980). Microfisica del poder. Ediciones de la Piqueta, Madrid. -(2014). Historia de la locura en la época clásica. Fondo de Cultura Económica, México.

Freidson, E. (1978). La profesión médica. Un estudio de sociología del conocimiento aplicado (ed. original 1970). Ediciones Península, Barcelona.

Gisbert C.; Arias, P.; Camps, C.; Cifre, A.; Chicharro, F.; Fernández, J.; González, J.; Mayoral, F.; Moro, J.; Pérez, F.; Rodríguez, A. y Uriarte, J.J (2002). Rehabilitación psicosocial del trastorno mental severo: situación actual y recomendaciones. Asociación Española de Neuropsiquiatría, Madrid.

GOFFMAN, E. (2001). Internados: ensayos sobre la situación social de los enfermos mentales (ed. original 1961). Amorrortu Editores, Buenos Aires.

- (2006b). Estigma. La identidad deteriorada, Amorrortu Editores. Buenos Aires.

Hacking, I. (1985). Making up people. (pp. 161-171). Reconstructing Individualism, Stanford University Press.

- (1995). Rewriting the Soul: Multiple Personality and the Sciences of Memory. Princenton University Press, Princeton.

- (1996). Representar e intervenir (ed. original 1983), Paidós, México. 
- (1998). Mad Travelers. Reflections on the Reality of Transient Mental Illnesses. University Press of Virginia, Charlottesville \& London.

- (2001). ¿La construcción social de qué? Paidós, Barcelona.

- (2004). «Entre Michel Foucault y Erving Goffman: entre el discurso en abstracto y la interacción cara a cara». Economía y sociedad, Volumen 33, Número 3, Agosto, 277-302.

HaLL, W. (2007). Discontinuación del uso de drogas psiquiátricas: una guía basada en la reducción del daño. The Icarus Project \& Freedom Center, Massachussets.

Haro, J. A. (2000). «Cuidados profanos: una dimensión ambigua en la atención de la salud». Medicina y cultura (pp. 101-161). Edicions Bellaterra, Barcelona.

Hopper, K.; Harrison, G.; JanCA, A. y SARTorius, N. (2007). Recovery from Schizophrenia: An International Perspective: A Report from the WHO Collaborative Project, the International Study of Schizophrenia. Oxford University Press, Oxford.

Huertas, R. (2012). Historia cultural de la psiquiatría. (re)Pensar la locura. Catarata, Madrid.

- (coord.) (2017). Psiquiatría y antipsiquiatría en el segundo franquismo y la Transición. Catarata, Madrid.

Kleinman, A. (1980). Patiens and Healers in the Context of Culture (ed. original 1980). California University Press, Berkeley.

LACAN, J. (2005). Escritos I. Acerca de la causalidad psíquica. Siglo XXI, Buenos Aires.

LANTERI-LAURA, G. (1972). «La chronicité dans la psychiatrie moderne française. Note d'histoire théorique et sociale». Annales. Economies, sociétés, civilisations, $27^{\circ}$ année. N. ${ }^{\circ}$ 3, 548-568.

Laplantine, F. (1979). La etnopsiquiatría. Gedisa, Barcelona.

Lemert, E. (1967). Human Deviance, Social Problems and Social Control. Prentice-Hall, Englewood Cliffs.

Martínez-Hernáez, A. (1998). ¿Has visto cómo llora un cerezo? Pasos hacia una antropología de la esquizofrenia. Universitat de Barcelona, Barcelona.

-(2006). «Cuando las hormigas corretean por el cerebro: retos y realidades de la psiquiatría cultural». Cad. Saúde Pública, 22(11), 2269-2280. 
Moncrieff, J. (2013). Hablando claro.Una introducción a los fármacos psiquiátricos, Herder, Barcelona.

Novella, E. (2017). «La psiquiatría franquista y la educación para la salud mental». Comelles, J. M. y Perdiguero-Gil, E. Educación, comunicación y salud. Perspectivas desde las ciencias humanas y sociales (pp.81-103). Publicacions URV-MARC, Tarragona.

Organización Mundial de la Salud (2018) [En línea]. Organización Mundial de la Salud (OMS). (Mayo de 2018). Disponible en <https://www.who. int/es/news-room/fact-sheets/detail/mental-disorders $>$.

PAYER L. (1992). Disease-mongers: how doctors, drugcompanies and insurers are making you feel sick. Wiley and Sons, New York.

Pérez Álvarez, M. (2014). Volviendo a la normalidad. La invención del TDAH y del trastorno bipolarinfantil. Alianza Editorial, Madrid.

PRIETO OREJA, J. (2016). Un estudio etnográfico sobre el reingreso de pacientes con patología mental en una unidad de hospitalización psiquiátrica en Extremadura. UEX, Badajoz.

Peset, J. L. (1983). Ciencia y marginación. Sobre negros, locos y criminales. Crítica, Barcelona.

Vispe, A.; Hernández, M.; Ruiz-Flores, M. y García-Valdecasas, J. (2015). «De la psicosis aguda al primer episodio psicótico: rumbo a la cronicidad.» Rev. Asoc. Esp. Neuropsiq. 35 (128), 731-748. 